\title{
METHOD OF IDENTIFYING THE REAL STATE OF THE COUNTER VEHICLE BASED ON THE INTERPRETATION OF ELECTRICAL SIGNALS
}

The article presents the analysis of electrical signals and system reports of motor vehicles in which the mileage counter indication has been questioned under service conditions as compared to the vehicles mechanical wear and tear. The essence of the aforementioned deliberations is an attempt at determining the universal procedures allowing for obtaining data concerning the actual vehicle mileage. Search for the intended method results from many factors functioning on the used motor vehicle market. The major factor is the uncontrolled safety level on the roads among the road users and, equally important, financial frauds in the area of motor vehicle sales, as well as vehicle cost estimation by the insurance companies.

Keywords: Vehicle mileage, technical condition, mechanical wear and tear.

\section{Introduction}

According to the data collected by the company 'Motoraporter', involved in the technical expertise of the used motor vehicles all over the territory of Poland, the 2014 summary presents the proportions described below [1]. During the year about 1000000 transactions were registered on the used motor vehicle market, among which $23 \%$ constituted domestic origin vehicles and $77 \%$ were the imported vehicles. The relation of transactions between private persons and dealers was $32 \%$ and $68 \%$ for second-hand car dealers and dealer's markets. The percentage of Poles purchasing motor vehicles from car dealers is minor, nevertheless, it is worthwhile to state that majority of the cars purchased by Polish people is $4-8$ years old (53\% of all inspected vehicles). For the purpose of comparing, the percentage of inspected vehicles dated 1990 - 1995 was only 3\%. Cars dated 2011 and newer constituted $15 \%$ of all inspected motor vehicles. Last year the station wagon type of vehicles prevailed, and the most popular engine was Diesel (increase from $60 \%$ to $72 \%$ ). The mileage of the inspected vehicle is a curiosity. The greatest number of vehicles, among the inspected ones, constitute those dated 2006 - 2010. We also know that imported vehicles constitute the majority. According to the statistics, a European annually drives about $30,000.00 \mathrm{~km}$. Relatively, it means the mileage between $120,000.00$ and $240,000.00 \mathrm{~km}$. Among the inspected vehicles the declared mileage usually was between 101000 and $150000 \mathrm{~km}$. The mileage exceeding $200000 \mathrm{~km}$ was very rare $(6 \%$ of the inspected cars), and if we would like to follow the statistics, it should possibly occur regularly. It has been also confirmed by the reports prepared by the company experts, informing that over $35 \%$ of the inspected vehicles had 'fraudulent' indications of the mileage counter. The data above present that the procedure of lowering the mileage counter indication, in spite of being illegal, is commonly employed, which in turn means the overestimation of the vehicle value and drastic decline of the safety level.

\section{Interpretation of signal drive system}

The implementation of the continuously increasing ecological requirements has forced the motor vehicle manufacturers to exceptionally develop as regards the internal combustion unit metering and the permanent supervision over its operating parameters. The technological advancement and the toxic substance emission limits have also caused the complete alteration of the diagnostic procedures applied for the contemporary vehicles. The necessity of applying modern diagnostic tools such as diagnoscopes dedicated to car brands, or universal tools, allow for the real-time viewing of the unit operation parameters, by means of the serial diagnostics method, with the application of the CAN bus. The limited life span of particular combustion unit components resulting from their precisely calculated number of work cycles in order to maintain the correct ecological parameters is a perfect tool to make an attempt at deducing the actual vehicle

\footnotetext{
* Pawel Olszowiec, Miroslaw Luft

Faculty of Transport and Electrotechnik, University of Technology and Humanities in Radom, Poland

E-mail: p.olszowiec@urhrad.pl
} 


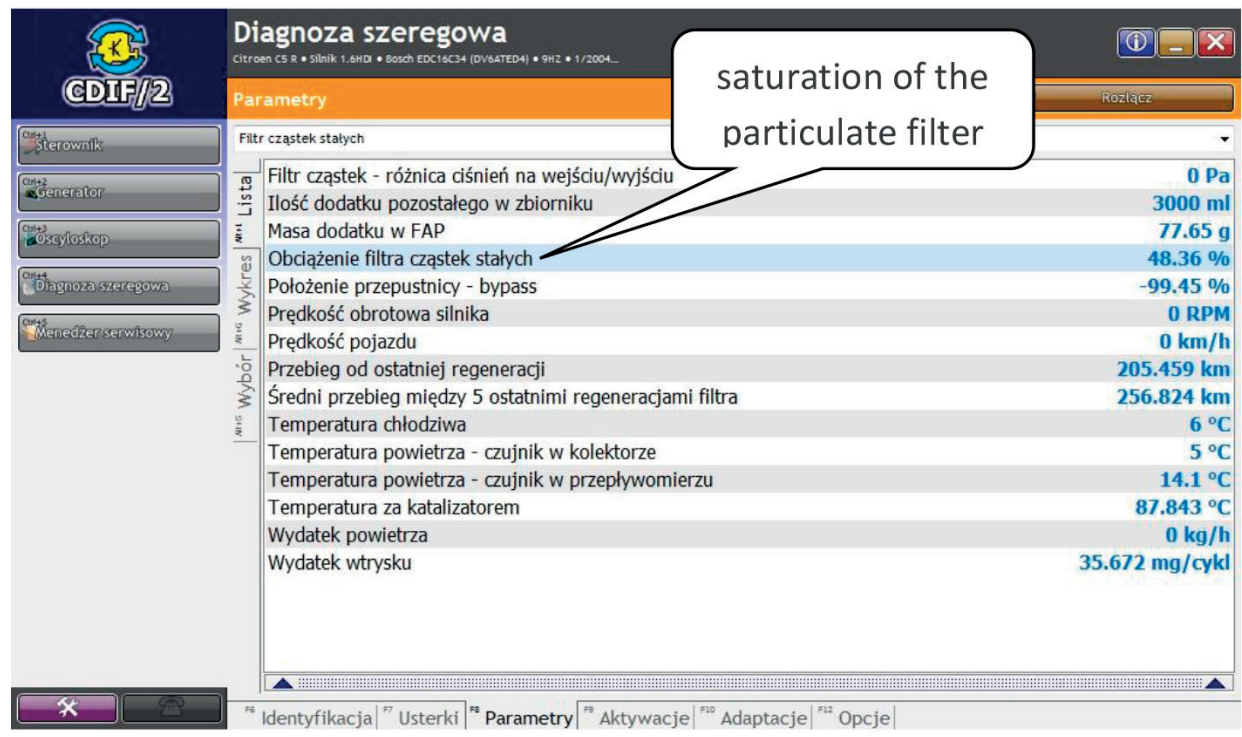

Fig. 1 CDIF2 Diagnostic Program window - diesel particulate filter saturation and the regeneration process regularity of the PSA Group vehicle readout [2]

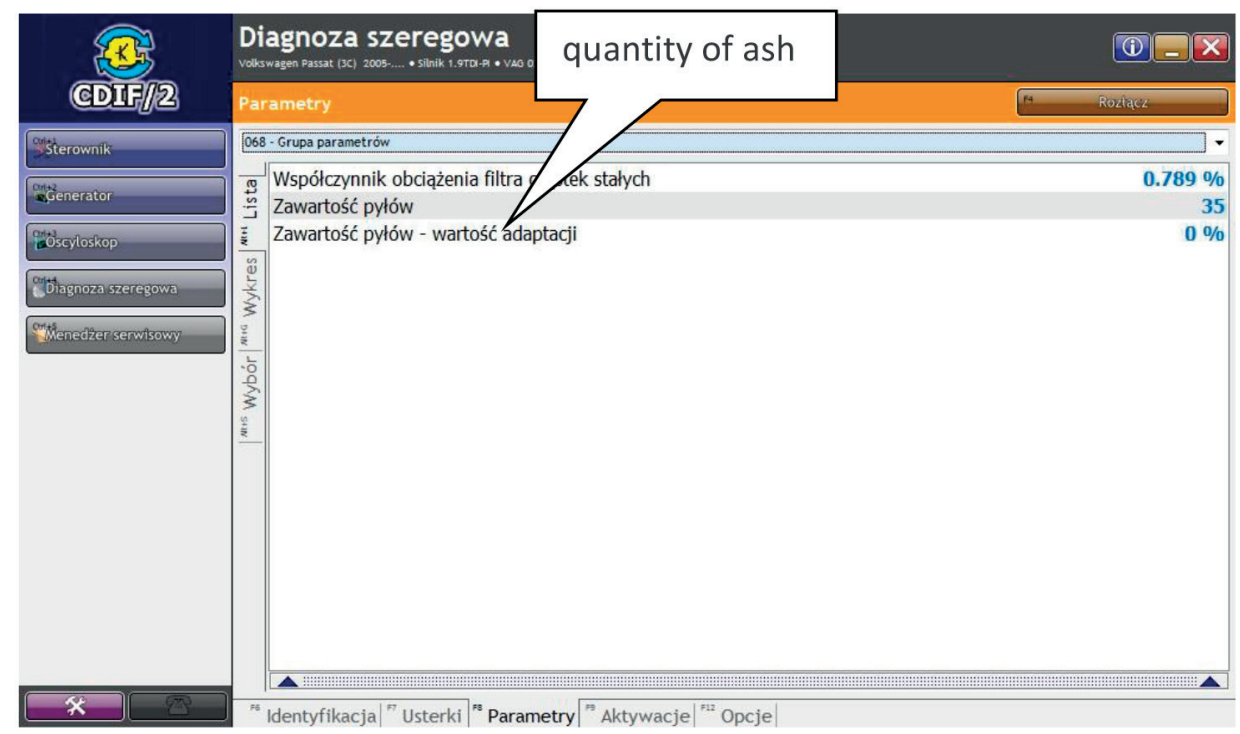

Fig. 2 - CDIF2 Diagnostic Program window - dust content parameter for the PSA Group vehicle readout [2]

mileage. It is applicable to the spark-ignition engines as well as to the compression-ignition engines. One of the elements which is directly connected to the mileage is the dust saturation of the diesel particulate filter in compression ignition engines (Fig. 1).

This parameter informs the diagnostician not only about the environment in which the vehicle was driving, but also about the number of successful regeneration processes, therefore, what the approximate vehicle mileage is. Nominal DPF/FAP type filter is prepared for the maintenance-free mileage of about 350,000.00 $\mathrm{km}$. For example, for the 1.9 TDI unit, engine code BLS, power
$105 \mathrm{~km}$, VW Group, the foregoing mileage means the dust content at the level of $35 \mathrm{~g}$ (Fig. 2).

Which is more, the significant element indicating the condition of the system for cleaning fumes from the carbon particles is the regeneration frequency and regeneration interval factor. In case of an attempt at the mechanical disposal of dust, there will remain information in the control concerning the interval between burning. Another element, which directly influences the vehicle mileage, is determination of the vehicle injection system condition - compression-ignition engine. The 


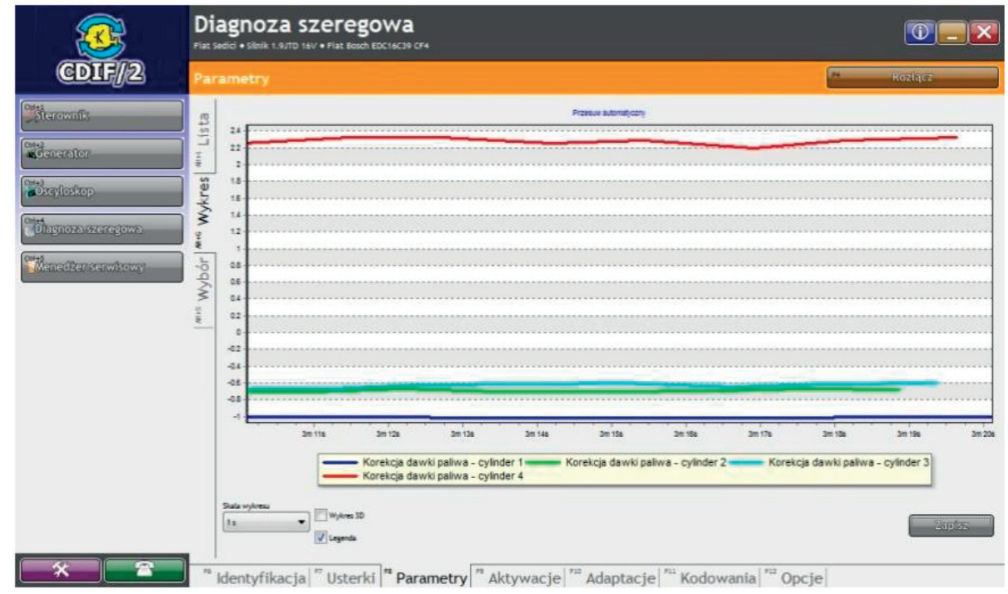

Fig. 3 CDIF2 Diagnostic Program window - graphic visualisation of the fuel injection correction for vehicle Fiat 1.9 JTD [2]

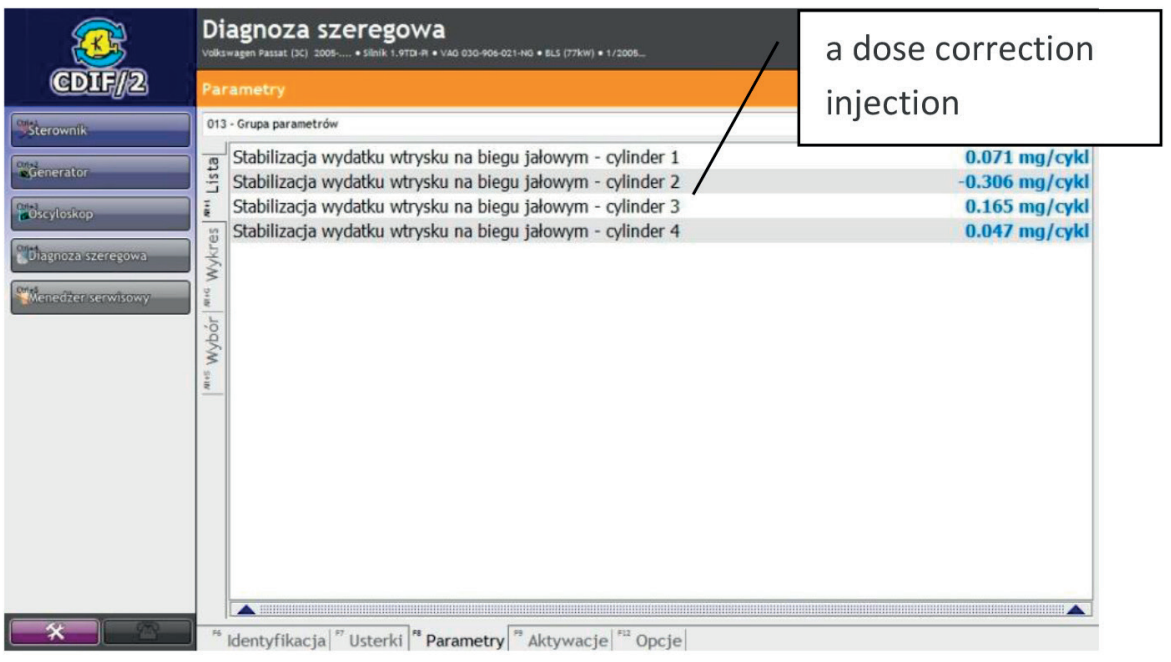

Fig. 4 CDIF2 Diagnostic Program window - fuel injection dose stabilisation parameters readout [2]

example of such a case is the fuel injection correction parameters readout on the particular fuel injection valve. At the moment the parameters, as in Fig. 3 are obtained, which means the significant discrepancy on the single injection, such state means the system damage and breakdown.

Another case is to identify the state of even balance of the significant injection dose corrections (value of about $+/-1 \mathrm{mg}$ ). Such a state means the even wear and tear of the fuel injection valves, which in turn means the significant vehicle mileage. The example of the balanced readout of the injection dose correction parameters is presented in Fig. 4, which shows the data of VW Group vehicle, 1.9TDI unit, BXE code with the mileage of $165,000.00 \mathrm{~km}$.

In case of the attempt at the mileage identification of the spark-ignition engine vehicle, it is crucial to try to determine the catalyst system wear and tear and inertia condition of the oxygen controlling sensors (lambda probes). Similarly to the diesel particulate filter, the three-way catalyst system efficiency is scheduled for a particular number of cycles equal to the mileage of about $180,000.00-250,000.00 \mathrm{~km}$. The voltage or current signal (Fig. 5) is the parameter indicating the catalyst wear and tear, depending on the oxygen sensor type - lambda probe.

The window above constitutes the presentation of the current scale of broad band oxygen sensors in the VW Group car with the spark-ignition engine with the direct injection of the TFSI type fuel. It is worth to note that the value of the actual vehicle mileage is among the parameters connected with the fume cleaning system. It corroborates the rule concerning the dispersion of data concerning mileage in various system modules. However, this issue is going to be analysed in more detail in the subsequent 


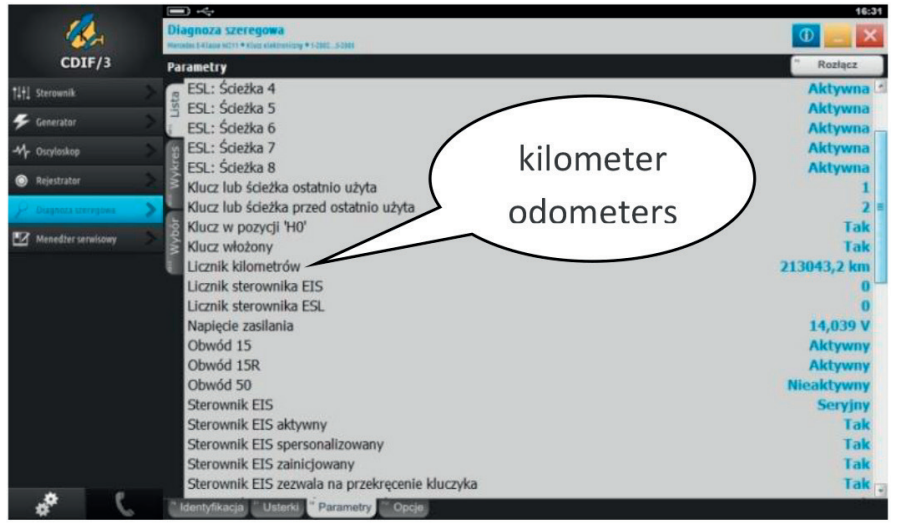

Fig. 7 CDIF3 Diagnostic Program window - Actual parameters of the key module readout vehicle MB W211 [2]

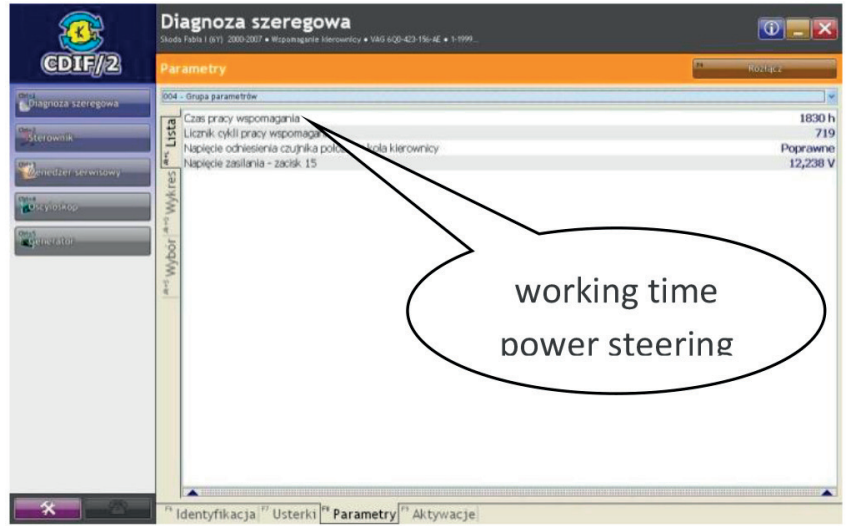

Fig. 8 CDIF3 Diagnostic Program window -- hours of operation in the power steering system readout VW Group vehicle [2]

chapter. Figure 6 constitutes the presentation of the registered breakdowns connected with functioning of the catalyst system and lambda probes.

The exceeding of the probe voltage maximum may be the sign of the fuel injection system damage as well as the wear and tear resulting from the exceeded operation cycles. The complementing inspection is the visualisation of the probe voltage signal on the diagnoscope. If the obtained chart does not reach the time amplitude below 1 second with 2000 revolutions per minute of the internal combustion unit, it will mean the lost inertia of the oxygen sensor, resulting from its wear and tear.

\section{The compatibility meter state between the different vehicle systems}

The already mentioned in the first chapter mileage dispersal system ensures the possibility of obtaining access to the vehicle mileage readout in various electronic modules. Apart from the mileage indication in the vehicle mileage counter, it is placed in the following components: key (Fig. 7), engine driver, power steering module, air conditioning, or xenon light driver.

Such dispersal of the mileage information has two objectives. First of all, the vehicle mileage parameter is, indeed, an important information for the module functioning, e.g. in the key, since it registers precise date and course of the damage occurring in the vehicle to be data carrier for the service purposes. Functioning information concerning the vehicle mileage in the light module allows for the active control over the light source wear in order to maintain the optimum safety level. Registration of the mileage parameter in the power steering module is done by means of the hours of operation registration. That is why, for example in the vehicle where the operation of the electric and hydraulic power steering amounted to 1830 hours (Fig. 8), in order to obtain the approximate vehicle mileage, you have to multiply the hours of operation by average local roads driving speed. In Poland this value is assumed to be at the level of $45 \mathrm{~km} / \mathrm{h}$.

The obtained value should be close $+/-5 \%$ to the mileage counter indications. Of course the extent of the problem, not only in Poland but also in Europe, is so high that there are first diagnoscopes available on the market with the function of 
the mileage readout from the engine module, e.g. EDC16 and comparing it to the mileage counter indication. Even though many discrepancies could be seen only on the basis of this example, the comparison of two modules is still not enough. The proper certainty level as to the mileage could be ensured by the tester allowing for the comparison of the mileage data taken from all available in the vehicle modules and the tester assessing the consistency of such indications.

\section{Summary}

In this work, the main sources of readout of the electrical data directly connected with the vehicle mileage have been indicated on the basis of many car manufacturers. The analysis of the aforementioned data allows for proposing a thesis that there is a possibility of defining quite precisely the actual vehicle wear level on the basis of the interpretation of the actual parameters connected with the driving unit and the remaining system modules functioning within the vehicle. It seems to be reasonable to make an attempt at defining common directions and procedures allowing for straightforward and consistent description of the vehicle mileage, in order to reduce the wheedling of money from the insurance companies and to increase the Polish roads safety.

\section{Reference}

[1] http://motoraporter.com/uploads/pressroom/pod_2014/podsumowanie_2014_roku_na_rynku_samochodow_uzywanych.pdf

[2] OLSZOWIEC, P.: Training Materials - Diagnoscopes, Radom, 2013. 